Article

\title{
Sustainable Innovative Project Management: Response to Improve Livability and Quality of Life: Case Studies: Iran and Germany
}

\author{
Hamid Doost Mohammadian ${ }^{1, *}$ and Fatemeh Rezaie ${ }^{2}$ \\ 1 Management Department, University of Applied Sciences (FHM), 33602 Bielefeld, Germany \\ 2 Management Department, Worcester and FHM University, 44801 Bochum, Germany; \\ baharrezaie70@gmail.com \\ * Correspondence: Doost@fh-mittlestand.de; Tel.: +49176-20826905
}

Received: 30 July 2019; Accepted: 26 September 2019; Published: 29 September 2019

\begin{abstract}
Nowadays, quality of life and livability are controversial phenomenon. A high quality of life and livability are demanded in cities; however, rapid and unplanned urbanization creates a lot of challenges such as poverty, slums, social instability, insecurity, diseases, environmental challenges and climate change, unemployment, economic problems, etc., which threaten the livability of the world. Therefore, it is vital to tackle urbanization challenges and create a sustainable urban setting with a high quality of life in order to make the world a better place to live. In particular, literature reviews, surveys, exploratory case studies, and the Kiwi and Kampenhood methodology based on Persian Zarathustra that is utilized in social science, engineering and management are the main method tools in this study. Fundamentally, modern livable and sustainable urban settings are suggested as a path to deal with urbanization challenges in order to improve livability and quality of life. Although sustainable cities provide opportunities to improve quality of life, urban planning and good governance with effective regulatory frameworks to create such modern settings are required. Thus, an innovative sustainable project management is introduced as a tool to design modern livable and sustainable areas. Innovation is declared as an accelerator to achieve sustainable project management in this research.
\end{abstract}

Keywords: innovation; sustainable innovative project management; sustainability; sustainable development; quality of life; livability; urbanization challenges

\section{Introduction}

Nowadays, people are moving to cities to benefit from more opportunities such as jobs, better education, improved health, etc., in order to gain a better quality of life. Although people prefer urban life, rapid and unplanned urbanization causes a lot of problems such as poverty, slums, environmental problems, climate change, social instability, economic problems, and diseases. These problems are significant threats not only for the future of the world, but also for human beings. In particular, these challenges reduce sustainability and livability of urban life by disturbing nature, the environment, and increasing risks related to human beings.

Quality of life and livability are the most important parameters concerned with human life. Quality of life is about life satisfaction and livability is concerned with health, wealth, security, safety, education, job opportunities, public services, transportation, recreation, housing, and environmental quality. So, quality of life and livability are related to human beings and their lives. Therefore, it is important to improve quality of life and livability in urban settings. There is a relationship among quality of life, livability, and sustainability. In other words, achieving high sustainability and sustainable development are tools to create better urban settings through tackling urbanization challenges. So, 
achieving sustainability is a path towards a higher quality of life and livability. In general, to gain sustainability, proper techniques and tools are required. In recent decades, the role of project management in developing sustainability has been introduced.

Fundamentally, sustainability is needed to tackle urbanization challenges in order to create modern livable urban settings with a high quality of life. This phenomenon is one of the controversial issues these days. Several paths are introduced by researchers, planners, decision makers, and architects to develop sustainability. Based on the authors' studies, high sustainability is recommended as a solution to struggle with urbanization challenges. High sustainability is different from traditional sustainability which has three components: social, economic, and environmental. High sustainability has seven pillars including environmental sustainability, political sustainability, social sustainability, educational sustainability, cultural sustainability, technical sustainability, and economic sustainability. In particular, some of these indicators such as education, regulation, and sustainability-based value creation were suggested as mechanisms for sustainability; however, the authors have realized that all seven pillars are required for developing sustainability.

These days project management is introduced as a path to achieve high sustainability. As Figgie and his colleagues declared, management is a technique to implement strategies and policies. So, management plays important roles in developing sustainability. Project management is required in urban planning to create a sustainable urban plan as a solution to struggle with urbanization challenges. In other words, project management such as risk management, is needed to plan a sustainable, comprehensive, and strategic urban plan to not only deal with infrastructure and urbanization challenges, but also develop high sustainability in urban areas.

In this research, innovative sustainable project management is declared as a solution to deal with urbanization challenges and create new urban settings with a high quality of life and livability. In addition, this solution is explored, and a model is proposed which is concerned with sustainable project management as the key to improve quality of life. In general, based on the current research, innovation is an accelerator tool to design successful project management. It means that innovation plays an important role in planning sustainable project management as a path towards sustainable urban areas.

The primary goal in this research is to suggest a model concerned with innovation, sustainability, and project management to improve quality of life and livability. In order to achieve the main goal, two sub goals are proposed. The first sub goal is to make an innovation model through suggested innovation models, and the second aim of the research is to determine the parameters and indicators concerned with quality of life and livability.

\section{Background}

\subsection{Innovation}

Innovation is about the introduction of something new and useful. Generally, innovation is the embodiment, combination, or synthesis of knowledge in original, relevant, valued and new products, processes, or services. Fundamentally, innovation has three levels: invention, implementation, and product. The challenge is to cultivate and leverage innovation capabilities that continuously deliver innovations. All innovation begins with creative ideas. Innovation is defined as the successful implementation of creative ideas within an organization [1,2].

Innovation is not just about new products and technology. It is vital to improve business and make an economic situation profitable. In addition, innovation also includes new processes, new business systems, and new management methods that could influence productivity and hence growth [3].

\subsection{Innovation Models}

There are different ways to categorize innovation models. The period of development, resources, and the novelty of the innovation portfolio are the main indicators to classify innovation types.

The Figure 1 presents the most famous types of innovation models: 


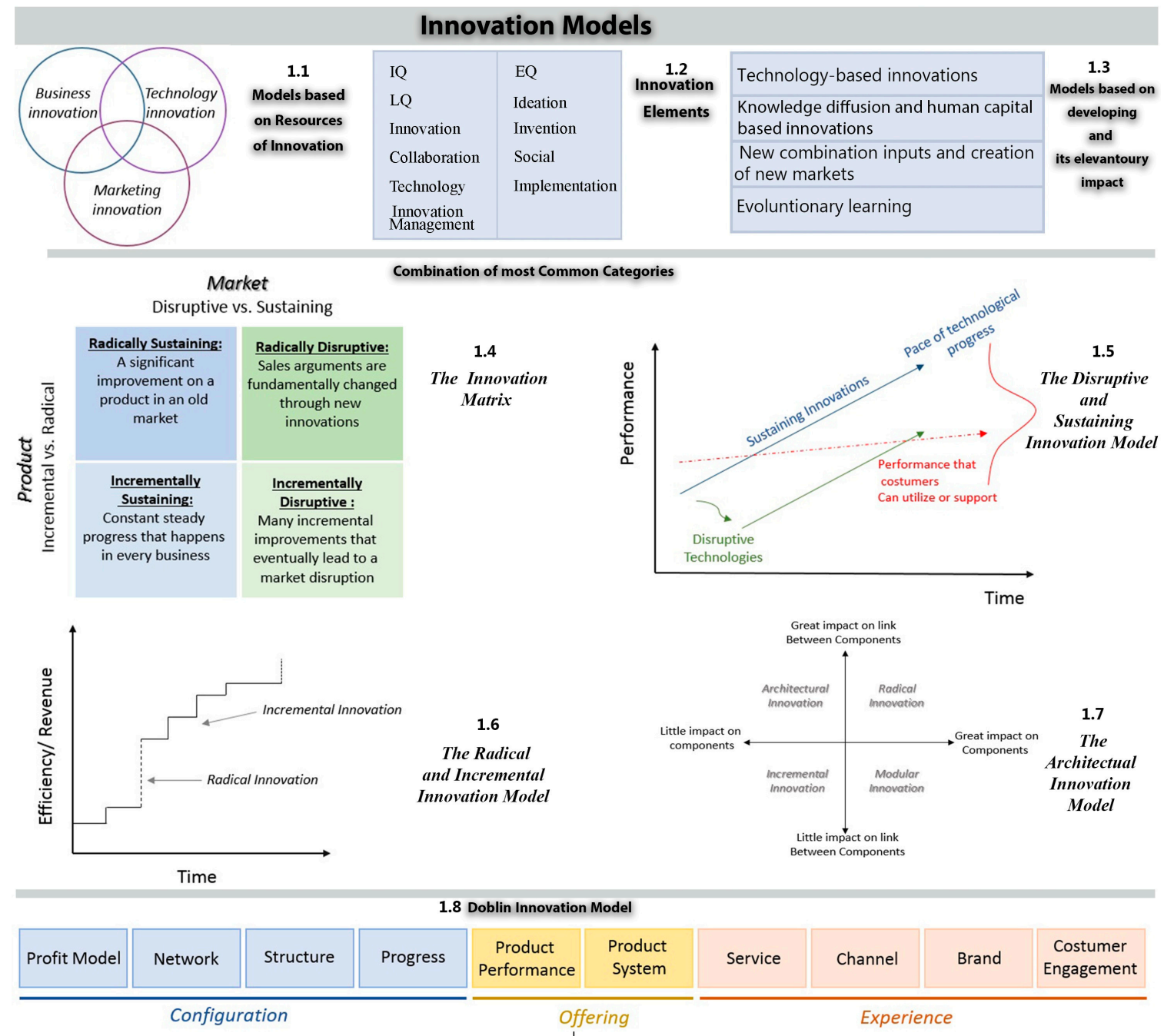

Figure 1. Innovation models [4-6].

In this research, innovation based on resources is selected as a tool to present an applied model. This category has three main elements:

$>$ Business model innovation:

This kind of innovation is concerned with rethinking the current business order to determine new revenue streams, revise them, and maintain competitive advantage. Promoting and improving businesses and looking to find new paths to gain new values is the way to achieve this model. Some systematic manners could improve business model innovation. These include analyzing the current business model, confronting your current business model, ensuring the consistency of a business model, building a pilot, and testing it [4].

\section{$>$ Technology innovation:}

Technological innovation is about creating new ideas and concepts through technology, capability, or knowledge in order to realize a new solution to a real or perceived need and to develop this solution into a viable entity. Utilizing new technologies has some privileges for businesses, such as accelerating innovation processes, finding out new possibilities on the market, creating new ideas and building them into innovations, modeling products and services for the market, and testing these new concepts [4].

$>$ Marketing innovation: 
Marketing innovation is one of the key elements for being successful in a business. This method is based on creating new markets, services and values that other businesses do not provide. Utilizing technology, new models for products, businesses, services, and enhancing existing offers are the main techniques to achieve this kind of innovation [4].

\subsection{Innovation Management Models}

Innovation is a tool utilized to make life more comfortable. Innovation is considered as the implementation of a new or improved product, service, or process, a new marketing method, or a new organizational method in business practices, workplace organizations or external relations. Innovation can influence management and therefore a new era named innovation management was introduced [7].

Innovation management is defined as the management of new ideas. To manage innovation, it is necessary to understand how it is implemented. Implementation is journey of an innovation from the beginning on to manufacturing, installation, activation and finally, evidence of clear business benefits [8]. Generally, innovation management is about improving the way an organization is managed in order to achieve its aims. Basically, the foundation of innovation management is innovation and creativity and its main goal is to alter the processes of the service or business towards a better path.

Innovation management makes new products, solutions, and services when changes in customers, industry, technology, economy, and society happen [9].

The main categories of innovation management models are:

- The Aachen Innovation Management Model AIM:

- Innovation Portfolio:

- Aachen Strategy Model for Product Innovation [10]

The most important roles of innovation management in businesses are:

1. Developing the innovative product or service

2. Building the business to market the product or service

3. Developing new business models to create new sources of income

4. Improving internal processes to enhance company form within or to save and reduce costs

The framework of innovation management is:

- Innovation strategy: This is concerned with strategic decision. Innovating strategy needs to make balances among value capture and creativity, incremental innovation and radical innovation, technological innovation and business innovation, internal innovation and external innovation.

- Innovation organization: This is concerned with organizational approaches such as linear innovation, systematic innovation, and dedicated innovation centers. In this step some questions should be answered:

$\checkmark \quad$ Where is innovation generated?

$\checkmark \quad$ Where could generation be generated?

$\checkmark \quad$ Where could each type of innovation be generated?

$\checkmark \quad H o w$ can innovations increase their chances to get through?

- Innovation systems: This contains the processes, teams, and networks. Innovation systems must be designed in order to perform the innovation strategy. Fundamentally, innovation systems expand the innovation culture. Innovation processes enable effective and efficient management of innovation in order to continue the improvement cycle. Idea management, innovation portfolio management, and innovation strategy follow up are introduced as main innovation processes. Innovation systems include innovation process teams, innovation project teams, internal innovation ecosystems, and external networks [11]. 
Fundamentally, innovation management is the combination of management and innovation processes in order to change management to make it better. It refers to products, services, business processes, and organizational processes. In addition, the focus is not only on the new, but also on the benefits of innovation $[11,12]$.

\subsection{Sustainable Development and High Sustainability}

For the first time in 1713, Carlowitz presented the new idea of sustainable. Then in the first half of the 18th century, the idea of sustainable revenue was published in Denmark, Norway, Russia, and France, but it was not until the 1970s that the idea of sustainability was officially stated [13,14]. In 1980 the idea of sustainable development was declared for the first time in the World Conservation Strategy drafted by the United Nations Environment Program (UNEP) and the International Union for the Conservation of Nature (IUCN). Then in 1995, Agenda 21 was presented, concerned with access to land, security of land tenure, tenants' rights, liberalized credit policies, and low-cost building material programs for 'sustainable' urban living for the homeless and for the urban poor [15]. Fundamentally, sustainable development occured in an effort to improve human well-being in the long term through management of the human environmental system [13]. Environment, economic, and social well-being are three traditional pillars of sustainability required to gain sustainable development. There must be an equilibrium to achieve sustainability [14].

Based on the authors' point of view, new definition for sustainability is required. Traditional pillars of sustainability are not enough to utilize as a tool to tackle urbanization problems these days. Thus, high sustainability was introduced as a new tool.

High sustainability is composed of seven pillars instead of the three pillars which make up the traditional notion of sustainability-environmental, economic, and social sustainability. Environmental, economic, social, cultural, educational, political, and technical sustainability are the main components of high sustainability. It is required that these seven pillars are developed fairly equally. In particular, two points are important for high sustainability:

The first point is that seven pillars including education, culture, social, technique, politic, economic, and environment are vital to gain high sustainability. The second point is that these seven pillars must develop almost equally. The Figure 2 shows these two points.
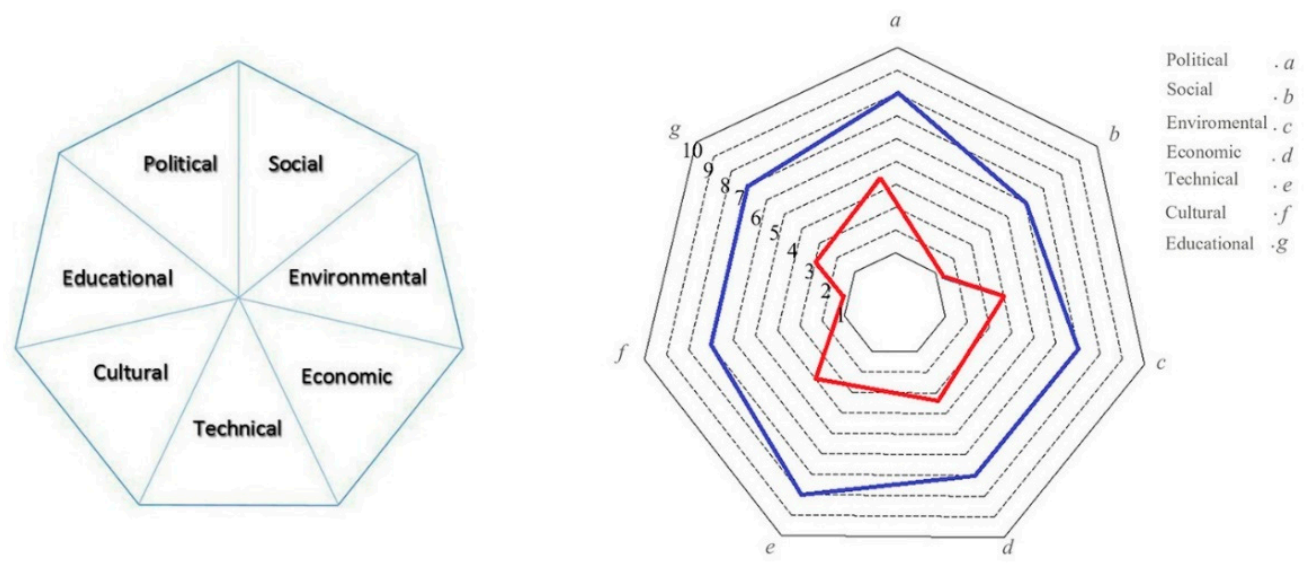

Figure 2. High sustainability [16].

\subsection{Sustainable Project Management}

Based on the research of Bebbington et al. and Singh et al. [15], there is a need for people, organizations, and companies to gain models, metrics, and tools to define and quantify sustainability through systematic forms and processes. In general, the development of sustainability indicators is required to achieve sustainability [15]. Studies show that there is a relation between sustainability and project success. Criteria of strategy, sustainability and safety could influence the success of a project. 
Future buildings and infrastructure would be evaluated on their operational flexibility, maintainability, and energy efficiency, so sustainability will have an impact on the well-being of their end users $[17,18]$. Projects could benefit from the sustainability perspective.

In order to integrate sustainability practice into project management, applying the following stages is needed:

- $\quad$ Utilizing sustainability expectations

- $\quad$ Reducing costs by creating new opportunities

- $\quad$ Utilizing sustainable risk management strategies

- Value maximization

- Sustainability requirements that are to be to accomplished

- $\quad$ Engagement to suppliers and sub-contractors

- $\quad$ Motivation for project tram [19]

Sustainable projects are one of the main goals of corporations and successful projects achieved by developing sustainability.

\subsection{Quality of Life}

In the last century, one of the most important issues pertaining to billions of people in both developing and developed countries is "Quality of life". It ranges from physical to socio-cultural, psychological and environmental. In particular, quality of life has three main features: First, it reflects the individual's conditions and their perceptions rather than a country's quality of life; secondly, it is a multidimensional concept, that includes multiple life domains such as housing conditions, education, employment, work-life balance, access to institutions and public services, and their interplay; and finally, it brings together objective information on living situations with subjective views and attitudes to provide a perspective of well-being in society [20].

Fundamentally, global challenges could worse quality of life, these include water and sanitation systems; solid waste management; transportation problems; pollution such as air and water contamination; land degradation; urban and industrial wastes; environmental hazards coming from natural sources, like earthquakes, floods, etc.; environmental hazards from human sources, such as accidents caused by industries, traffic, municipal facilities, and fires; and environmental problems of a global nature, like greenhouse gases, rising sea levels and climate change. In other words, global challenges threaten the quality of human life by making sustainability low and disturbing nature [21].

Generally, the quality of living environments can affect people's level of satisfaction and have impacts on their behavior. The places people live, from their dwellings to their neighborhoods and surrounding communities, impact their quality of life. Based on a study by van Poll [22], the quality of urban life is measured not only by physical aspects such as the quality of the built environment and its facilities, but also social aspects such as the human ties in the community. In other words, the quality of life is to be promoted, if sustainable development is applied and equal emphasis is given to economic, social, and environmental dimensions [23].

\subsection{Livability}

Livability has become a significant issue since the 1980s when people began studying shifts in development patterns from the decline of urban centers to rapidly growing suburban areas [21]. Heylen explained livability "as an umbrella to a variety of meaning, which depends both on the objects of measurement and the perspective of those making the measurement". According to her, livability is about the environment from the perspective of the individual and consists of a subjective evaluation of the quality of the place [24].

Quality of livability is measured with some factors such as political stability, safety, healthcare, education, public services, transportation, recreation, housing, and environmental quality $[25,26]$. Livability is a "place-based" idea related to indicators such as home, neighborhood or city that concern 
quality of life and well-being. Quality of life and well-being can be measured through an individual's living condition or state including economic well-being like human capital, quality of life indicators such as social capital, and qualitative expressions of personal satisfaction.

Generally, livability is used to describe the overall contribution of the urban environment that impacts on the quality of human life or well-being [25].

The principles of livability include (Figure 3):

- Provide more transportation choices;

- Promote equitable, affordable housing;

- Enhance economic competitiveness;

- Support existing communities;

- Coordinate and leverage federal policies and investments;

- Value communities and neighborhoods [26].

There is a relation between livability and sustainable development through indicators that are used to indicate livability under the ambit of a "cleaner, safer and greener" environment that are introduced as main components to achieve sustainable development. Sustainable urban development has four keys: livability and environmental sustainability, economic performance, and good governance. In many advanced economies livability has been adopted in a much narrower and more operational sense and has to do with high degrees of 'cleanliness, safety and green-friendliness' $[27,28]$.

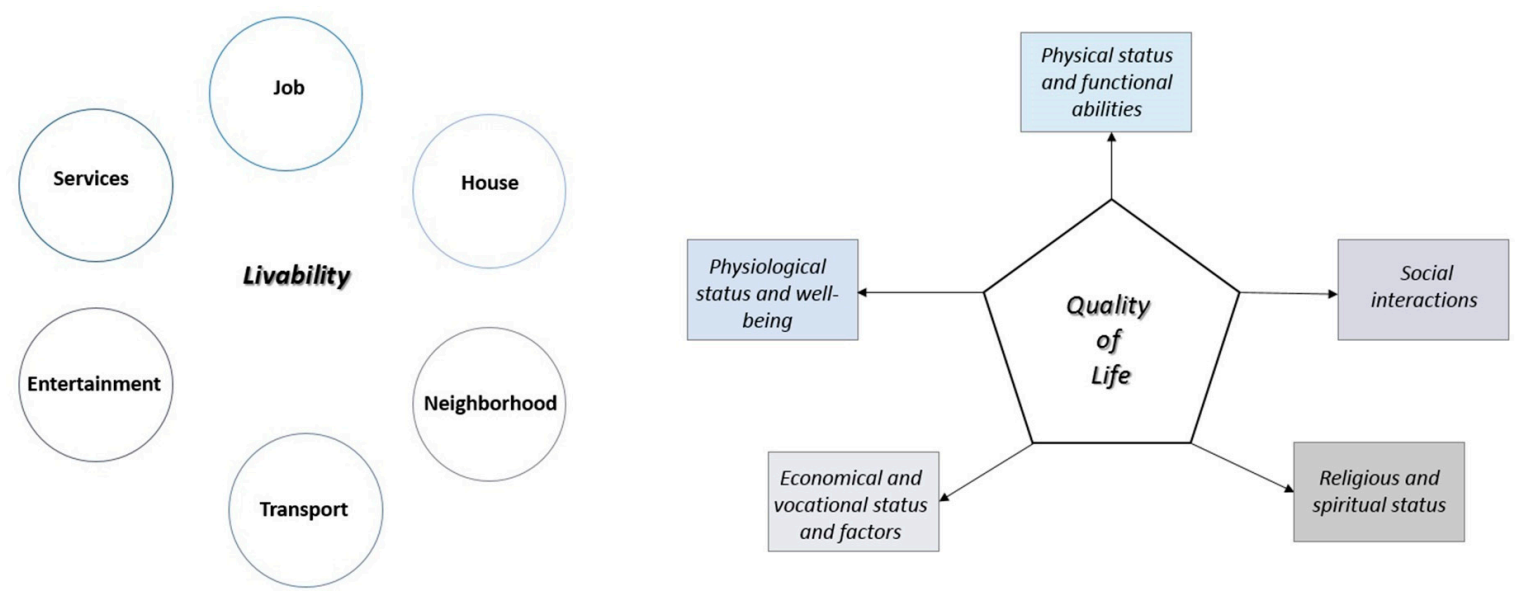

Figure 3. Aspects of quality of life and livability $[29,30]$.

\section{Methodology}

To address the aims of this research, some questions should be answered:

1. How would sustainable project management improve quality of life and livability?

2. How would quality of life and livability be threatened?

3. What are the roles of innovation models in achieving goals of a project?

4. Why is innovation sustainable project management vital for the world in these decades?

In order to answer the research questions and achieve the aims of this study, it is important to pursue a sound methodology. In this paper three stages were developed to implement the study:

Stage 1: The development of a research methodology

This stage was developed on the basis of the literature review in the area concerned on objectives of this research. The authors have thoroughly investigated papers published in the context of innovation, innovation management, sustainable project management, livability and quality of life. In addition, the importance of sustainable urban areas with a high quality of life and livability was explored. 
Stage 2: The development of the research tool

The research tool was developed on the basis of the relevant literature, exploring case studies, knowledge, and personal experience.

The purpose of surveys and case studies was to indicate policies, strategies, and solutions utilized by case studies in order to find out the roles of innovation, sustainable project management, and sustainable development in facing urbanization challenges.

In addition, the methodology of Kiwi and Kampenhood was used as a tool for analyzing. This method is used in social science, engineering, and management, and comes from Persian Zarathustra (good thoughts, good words, good deeds); it was selected as a methodology tool. In 2009, Hamid Doost Mohammadian used a dialectical thinking related to this methodology and designed a diagram to revise the method. In 2010 he translated it into English, although it is not yet officially published. Generally, the aim of this methodology is to find out factors influencing people's well-being. This methodology is based on three levels with seven questions and analysis had been done through these questions.

The Figures 4 and 5 present this methodology and its processes:

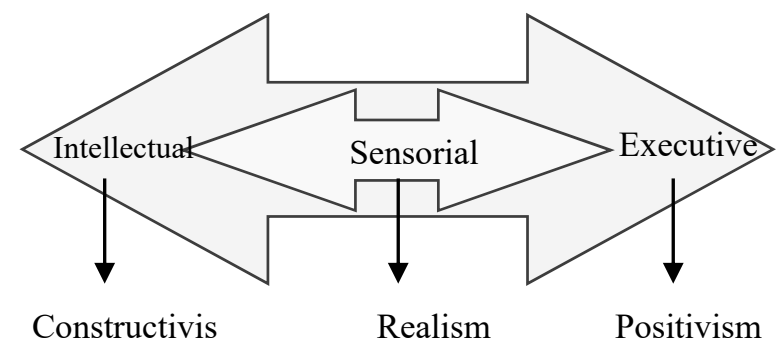

Figure 4. Kiwi and Kampenhood methodology [31].
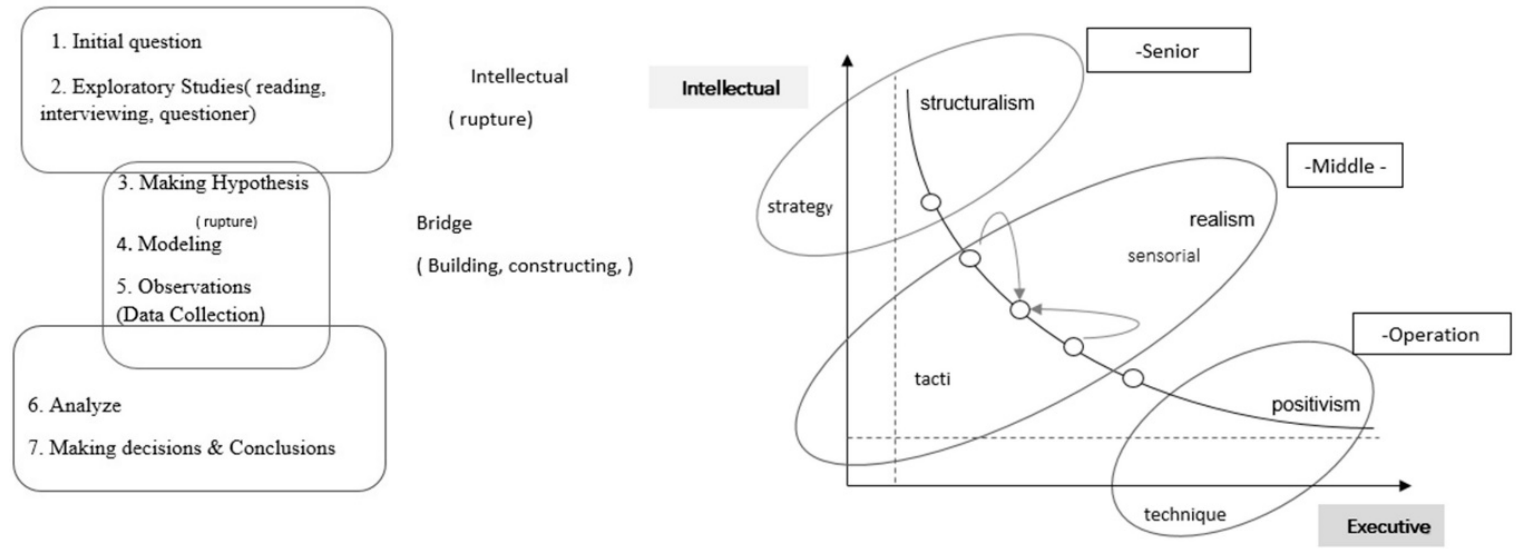

Figure 5. Revised diagram concerning Kiwi and Kampenhood methodology and its levels [31].

Stage 3: Gathering the study results and analyzing

Based on literature reviews, surveys, case studies and analyses, some results were obtained and these results were analyzed and discussed by the authors.

\section{Case Studies}

As was mentioned, quality of life and livability are concerned with life satisfaction, health, wealth, security, safety, education and job opportunities, public services, transportation, recreation, housing, and environmental quality. Although some countries like Germany create a high quality of life through achieving these indicators, developing countries such as Iran cannot create a high quality of life and livability for its citizens.

In this study, two countries are selected as case studies: Germany and Iran (Figure 6). Through different rankings (Economist, Mercer, Numbeo) Germany is ranked as one the most livable countries 
in the world; Iran's quality of life is very low, and it does not exist in most rankings. Generally, two countries that are different in sustainability and livability are chosen to create a proper context to find out which indicators make differences in quality of life and sustainability. Although there are more sustainable and livable countries than Germany, it was chosen as a case study in this study. The main reason to select Germany was that this country will be more sustainable and livable in the future through utilization of proper strategies and policies. These policies and strategies can be studied and used by less sustainable countries, like Iran, in order to improve their quality of life. In addition, Germany is a country that was not always as sustainable as it is now. After World War II, Germany confronted a lot of problems that threatened the future of the country. Germany struggled with these challenges through proper strategies, policies, management, education and appropriate governance and created a sustainable country with a high quality of life and livability. Thus, it is a good example to show low sustainable countries that they are able to change their situation by utilizing strategies and policies. These were the two main reasons that Germany was chosen Germany as a case study. Furthermore, the second country was chosen as a less sustainable country in order to determine the reasons why some countries are more sustainable than others. Iran was selected as the other case study because as a low sustainable country, it is the hometown of the authors and they are aware of its conditions. So, it was chosen as the second case study.

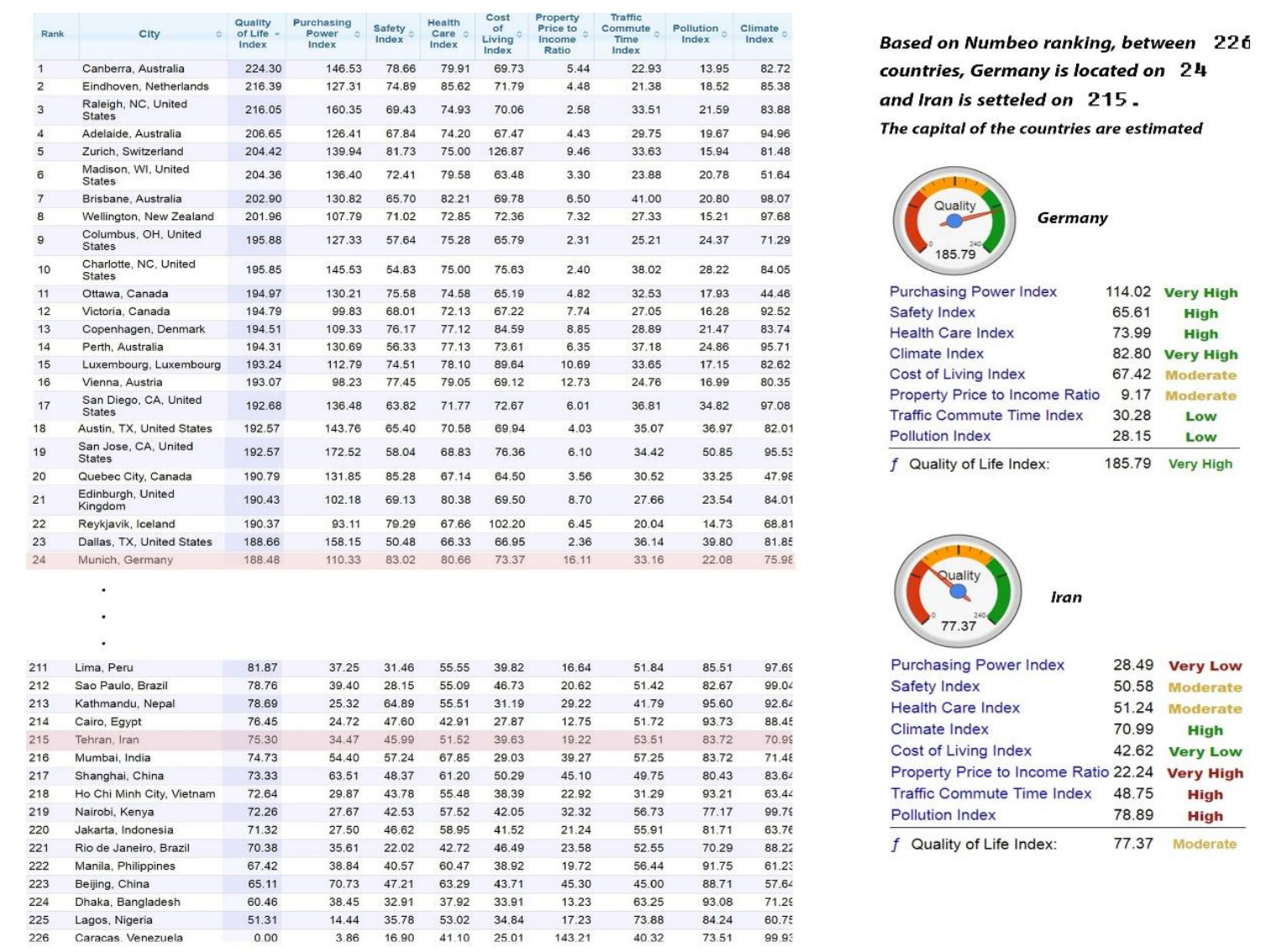

Figure 6. Quality of life and livability in Germany and Iran, 2019. (www.numbeo.com).

\subsection{Germany}

Generally, quality of life in an urban setting in Germany is high. Education and skills, work-life balance, jobs and earnings, income and wealth, environmental quality, social connections, civic engagement, housing, personal security and subjective well-being make cities in Germany very livable.

Strategies used in Germany make livability and a quality of life possible. For instance, free education, high profitable insurance, appropriate and sustainable transportation, existing jobs and other 
opportunities made through strategies, waste management, utilizing corporate social responsibility (CSR) by companies and governments, help to create a country with a high quality of life. Further, some innovative strategies include utilizing waste as energy resources, renewable energy, water collecting, resource management and educating children in a proper way. These innovative solutions promote a high quality of life.

Another innovative solution which has made Germany sustainable in the economy is successful small and medium sized enterprises (SMEs). SMEs in Germany are responsible for almost $40 \%$ of total German gross investments and account for $30 \%$ of the country's exports. Fundamentally, Germany is the second highest exporter in the world after China. According to high population of China, it could be declared that Germany is located at the first level of the export. More than $98 \%$ of companies in Germany are SMEs. This means that the economic situation depends on SMEs directly.

Innovative, entrepreneurial, and competitive international German SMEs focus on highly customized and specialized products and services via innovative strategies, high technologies, digitalization, productivity and exceptional vocational training system. SMEs can be used as tools to achieve sustainable development through productivity and growth of services, improving economic situations, enhancing social responsibility and social instability, reducing impacts of ecological footprint by innovative solutions concerned with green strategies in order to improve sustainability, more manufacturing, growth, job creation, international business and improving livability. Therefore, SMEs improve sustainable development. Truly, SMEs make Germany more sustainable with a high quality of livability and quality of life. Some factors for success of German SMEs are presented:

$>$ Internal secrets:

(1) Innovative spirit-innovation-driven enterprises

(2) Flexibility

(3) Flexible work force

(4) SMEs think in generations, not quarters

(5) Loyal, well-trained staff

(6) Conservative financial conduct

(7) Hidden champions

(8) Regionally embedded, but internationally oriented

(9) Vocational training

$>$ External secrets:

(1) Excellent regional education

(2) Adequate, regional financing, funding

(3) Well-developed infrastructure and high quality of life in rural areas

(4) Effective and competent local administrations

Therefore, strategies used by German SMEs are other solutions to make Germany a sustainable country with a high quality of life and livability.

Fundamentally, governments, companies, and businesses do their best to achieve needs concerning livability through proper strategies. In other words, urban and infrastructure strategic plans achieve sustainable development in the country as well as improve quality of life and livability.

\subsection{Iran}

Quality of life and livability is low in Iran. Livability is weighted by some main dimensions such as healthcare, stability, culture and environment, education and infrastructure quality. Fundamentally, these dimensions are low in Iran and the most important reason is improper strategies used by the government and businesses. For instance, income gaps lead to social instability and increase 
crimes in the country. So, security and safety become low and this directly influences livability in Iran. In addition, improper education reduces not only social and economic sustainability, but also environmental sustainability. For instance, skillful and expert capitals are required to create successful and sustainable businesses as the backbones of a country. So, education has an important role in improving the sustainability of a country. Political challenges such as sanctions disturb the sustainability of Iran. Exports and imports play significant roles in the economics of the country and sanctions weaken the export/import systems in Iran. So, one of the main backbones of the financial system becomes weak and creates significant threats to the economic sustainability of Iran. In addition, using old processes and management in businesses creates challenges for organizations to participate in the global market; this is yet another challenge that the economic system of Iran is confronted with.

In addition to these problems, environmental challenges such as air and water pollution, unsustainable infrastructure, poverty, slums, and depletion of resources such as fossil fuels are the main risks which threaten the future of Iran. The most important causes for Iran's environmental challenges are:

$>$ High consumption of fossil fuels instead of using renewable and clean energies

$>$ Utilizing low-quality gasoline and benzene (because of sanctions)

$>$ High household energy usage

$>$ Utilizing old techniques to refine water and producing energy

> Inappropriate lifestyles and improper education about the importance of environmental sustainability

$>$ Stereotyping and temporary solutions like canceling schools as a solution to air contamination

$>$ Industrial challenges including old processes, using natural resources, wastes of industry, etc.

$>$ Land mobility of dangerous and contaminated goods

$>$ Infrastructure challenges like mobility and transportation problems

$>$ Improper management

$>$ Inappropriate comprehensive strategic urban plan

These are the main reasons for the environmental challenges that Iran is confronted with. In particular, nominated challenges make sustainability and livability in Iran worsen. These challenges prevent Iranians from having their needs addressed which causes the citizens to not be satisfied with their situation in life. So, there are significant threats for future of Iran. These challenges need to be addressed by utilizing proper management, strategies, policies, comprehensive strategic plans, education and cultural norms in order to create a sustainable country. In particular, strategies and solutions used by sustainable countries like Germany can help Iran become more sustainable. In addition, innovation, high technologies such as IT, ICT, IoE, IoB, digitalization, skillful capitals and smart citizens could be used as tools to create a sustainable country.

Fundamentally, it is vital to make the quality of life and livability better in Iran by addressing the risks which threaten the future of Iran and improving sustainability.

\section{Results}

Based on researches, studies, exploring case studies and analyses of articles [26,32-40]; the following was concluded:

$\checkmark$ Urbanization challenges are significant threats for human beings. In particular, these challenges disturb humans from satisfying their needs and demands which influence quality of life and livability.

$\checkmark$ To improve quality of livability and life, it is required to deal with urbanization challenges. In addition to sustainability, other solutions are needed. Sustainable and innovative project management is introduced by the authors as a tool to tackle with these challenges.

$\checkmark$ Sustainable innovative project management is a tool to design a proper comprehensive strategic urban plan to create modern livable areas. 
$\checkmark \quad$ In this research, a new definition of sustainability was introduced — high sustainability-with seven pillars including economic, environmental, social, cultural, educational, technical and political sustainability. These are declared as proper techniques to overcome urbanization challenges. Based on the authors' point of view, traditional sustainability is not able to deal with these challenges; so, a new definition was presented.

$\checkmark \quad$ Sustainable innovative project management and high sustainability could tackle urbanization challenges and develop sustainability in order to improve quality of life. So, it could be concluded that there is a relationship among sustainability, livability, and quality of life.

$\checkmark \quad$ In general, sustainable innovative project management can create modern livable urban areas that are able to make the world a better place for living by reducing urbanization challenges and developing high sustainability.

\section{Discussion}

In this section, results of the research are discussed:

\subsection{Human's Needs, Livability, and Quality of Life}

Quality of life and livability are the most important parameters concerned with human life. Quality of life is about life satisfaction ranging from physical health, family, education, employment, wealth, safety and security to freedom, religious beliefs, and the environment; and livability is focused on health, wealth, security, safety, education and job opportunities, public services, transportation, recreation, housing, and environmental quality. So, quality of life and livability are indicators that are measured by quality of a human life and well-being.

Generally, quality of life and livability depend on human needs. Maslow's hierarchy of needs presents how human needs could influence quality of livability and life (Figure 7).

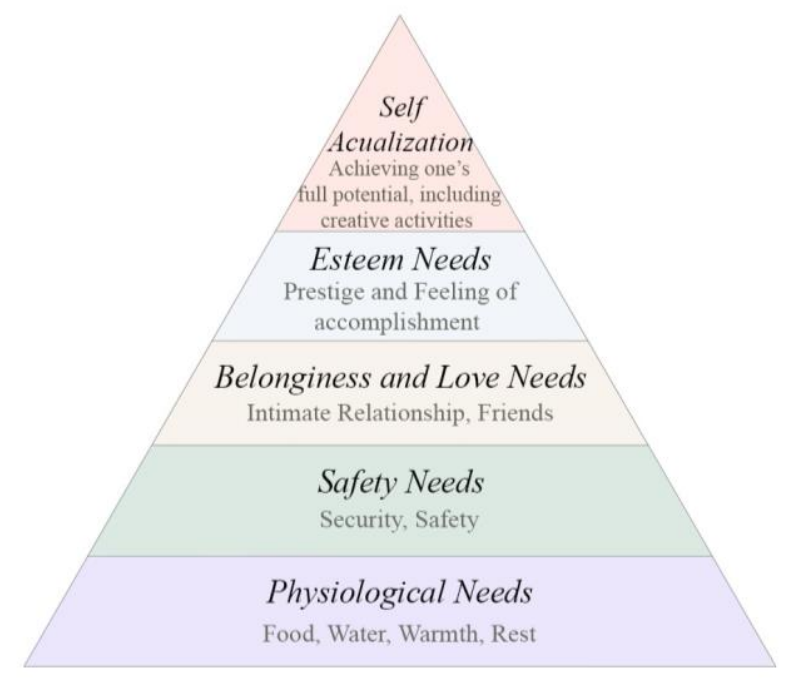

Figure 7. Maslow's hierarchy [32].

Maslow's hierarchy of shows human needs including physiological needs, safety needs, belonging needs, esteem needs and self-actualization that are related to livability. It means that supplying these needs would influence livability and improve quality of life. So, there is a relation among human needs, livability, and quality of life. In general, to make a country livable and improve quality of life, it is necessary to obtain these needs.

If Maslow's hierarchy is achieved, quality of livability and quality of life could be improved. When the highest levels of hierarchy are reached, a high quality of life is obtained. So, it is vital to find out the indicators concerned with Maslow's needs in order to obtain them and improve quality of life and livability. 
Nowadays, the world confronts a lot of problems, like urbanization challenges, that threaten human needs. These days, people are moving to cities to benefit from better jobs, education, economic, health, wealth and other opportunities. Generally, people prefer urban life to rural life because they have better opportunities in cities to improve their quality of life. However, the increasing population of cities poses significant threats to urban life and can lead to dissatisfaction by disturbing the different aspects of Maslow's hierarchy.

Through growing urbanization, Maslow's hierarchy of needs can face many difficulties. It means that urbanization problems such as poverty, slums, health diseases, environmental challenges and climate change, unemployment, social instability and others are directly related to Maslow's hierarchy of needs and could compromise quality of life in human beings. For instance, urbanization causes challenges concerned with supplying safe food, clean water, housing facilities, security, safety and sufficient energy as physiological needs. Generally, natural resources such as fossil energy resources will be depleted in the near future and it could influence the supply and demand. Further, fossil energy makes pollution and harms the environment and urban setting. In addition, economic problems such as unemployment, poverty, and economic instability as well as challenges related to public utilities will occur, just as Germany confronted economic challenges after WWII that were significant threats for this country. German SMEs struggled with economic problems but created one the most sustainable economic systems in the world.

Fundamentally, urbanization challenges prevent Maslow's needs from being achieved. This leads to people's dissatisfaction with their life, and quality of life and livability are reduced. Therefore, it is important to find solutions to struggle with these challenges to obtain Maslow's needs in order to improve quality of life.

Generally, Maslow's hierarchy of needs should be gained to create livable urban areas with high quality of life. Therefore, it is vital to find out solutions to achieve human needs through dealing with urbanization challenges.

\subsection{Sustainability and Human Needs}

In recent decades, rapid and unplanned urbanization has caused a lot of problems that threaten the future of the world and human beings. For instance, environmental challenges, climate change, depletion of resources, and health challenges not only lessen quality of livability but also the future of the world for people. So, solutions should be utilized to deal with these problems and supply human needs.

Human needs could influence on the quality of human life. In other words, if human needs based on Maslow's hierarchy of needs are not gained, quality of life and livability could decrease which then makes citizens dissatisfied about their lives. This is an important menace for the future of human beings. As was mentioned before, the path towards supplying human needs and tackling urbanization challenges are needed.

One of the best solutions determined in recent decades to struggle with urbanization is sustainability and sustainable development. Sustainable development can be used as a tool to manage and maintain natural resources, use renewable energy, reduce environmental challenges such as air pollution, water shortage and others, improve economic situations, and promote social responsibility, security and social stability. Sustainability can influence a city's infrastructure like transportation, mobility, economic, social stability, security, job and education opportunities, health, and environment and create sustainable infrastructure (Figure 8). Sustainable development and sustainable infrastructure supply Maslow's needs. So, sustainability can improve quality of life and livability through sustainable infrastructure. Fundamentally, a sustainable city is the solution to supply Maslow's needs and improve livability in an urban setting. 
- End poverty in all form

- End hunger, achieve food security and improved nutrition and promote sustainable agriculture

Ensure healthy lives and promote well-being for all

Ensure quality of education

Achieve gender quality

Ensure availability and sustainable management or water and sanitation for all

Ensure access to affordable and clean energy for all

Promote sustainable use of terrestrial ecosystem

- Conserve and sustainability use resources

Take urgent action to combat climate change and its impact

Ensure sustainable consumption and production patterns

Make cities and human settlements sustainable

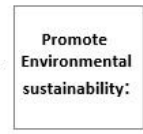

Promote sustainable growth and productive employment and decent work for all

Promote resilient infrastructure and sustainable industrialization

Promote peaceful and inclusive societies with access to justice and accountable

institutions

Strengthen implementation and global partnerships for sustainable development

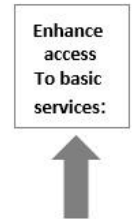

Sustainable

Infrastructure

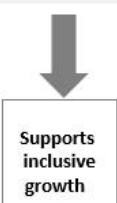

Environmental Sustainability

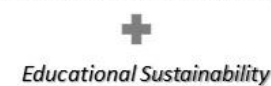

는

Economical Sustainability

단

Technical Sustainability

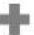

Political Sustainability

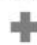

Cultural Sustainability

Social Sustainability

Figure 8. Sustainable infrastructure.

Sustainability is not sufficient to create sustainable livable urban areas. In other words, sustainability needs other tools in order to tackle urbanization challenges and supply human needs to create modern urban settings where high sustainability makes a high quality of livability and thus citizens are satisfied with their lives.

\subsection{Innovative Sustainable Project Management}

In addition to sustainability, other techniques are required to deal with urbanization challenges in order to create sustainable livable urban areas. Based on the authors' researches and analyses, sustainable project management could be used as a proper tool.

Project management is able to balance time, scope, and cost regarding quality. Thus, project management helps projects be successful. In addition, it could be a tool to develop sustainability.

Generally, project management would help projects be sustainable through resource management, strategic plans, and risk management.

Resource management focuses on natural resources, capital resources, human resources, financial resources, agricultural resources, and generally resources related to land, labor and capital resources in a country. Resource management includes acquiring, allocating, and managing resources. It is used to improve efficiency and profitably of businesses. In addition, it is a key to improve environmental challenges. Generally, the first step in project management is resource management required for proper planning.

Strategic planning is another element of project management. It is concerned with an organization's goals. Strategic plans could help businesses, organizations, and governments to achieve their goals. A proper strategic plan is concerned with financial, environmental, social, cultural, educational, technical and political aspects as well as CSR. In other words, strategic plans should focus on all aspects of sustainability to achieve its goals.

Risk management is needed to analyze risks related to strategic plans and reduce project failure. Generally, four types of risks such as project risk management (PRM), financial risk management (FRM), enterprise risk management (ERM), and government risk management (GRM) should be utilized to reduce failure of a project and gain the best results.

Sustainable innovative project management is required to make policies, strategies, solutions, and keys to gain the best result and sustainability through project management.

Sustainable project management is about changing policies, strategies, assets and organization concentered on all aspects of sustainability, in order to deal with urbanization problems in order to improve quality of livability and life.

To gain sustainable project management, accelerators like innovation play important roles. Innovation is not only about new ideas, but it is also concerned with the improvement of the process. 
Innovation can help change and improve project management strategies. In other words, innovation can influence and improve project process, strategies related to sustainable development, and elements of project management. Generally, innovation uses external and internal opportunities and creativity to improve old processes or introduce new concepts as new processes. In addition, innovation can create new models related to sustainability, project management, and quality of life. These models can help countries, especially developing countries, to overcome their problems and improve their quality of life and livability in the best and fastest way. Although sustainable project management is a proper tool to improve quality of life, sustainable innovation project management is a better tool that gives results faster and in the most precise way.

Fundamentally, innovative sustainable project management is introduced as a solution to create modern urban areas in order to improve quality of life and livability. Based on this solution, a model is proposed.

DR-ISPM is introduced by the authors as an innovative sustainable project management model. This model shows that required sustainability aspects are located in the project triangle.

The aim of management is to make a balance among time, cost and scope to gain the best quality. When a project is parallel with social, economic, and environmental sustainability, then sustainable project management is achieved. In other words, if management is aligned with sustainability aspects, sustainable project management will be gained. In addition to sustainable project management, innovation in business, marketing and technology could play roles in creating innovative solutions. As was mentioned, to gain sustainable project management, accelerators like innovation and high technology are required. According to this model, sustainability and management created through innovation could create a path towards a high quality of livability and life. Fundamentally, this model could be used as a strategy in a comprehensive strategic urban plan to work with sustainability in order to design modern sustainable and livable urban settings.

The Figure 9 presents the DR-ISPM model as a theory to improve quality of life and livability through sustainable innovative project management.
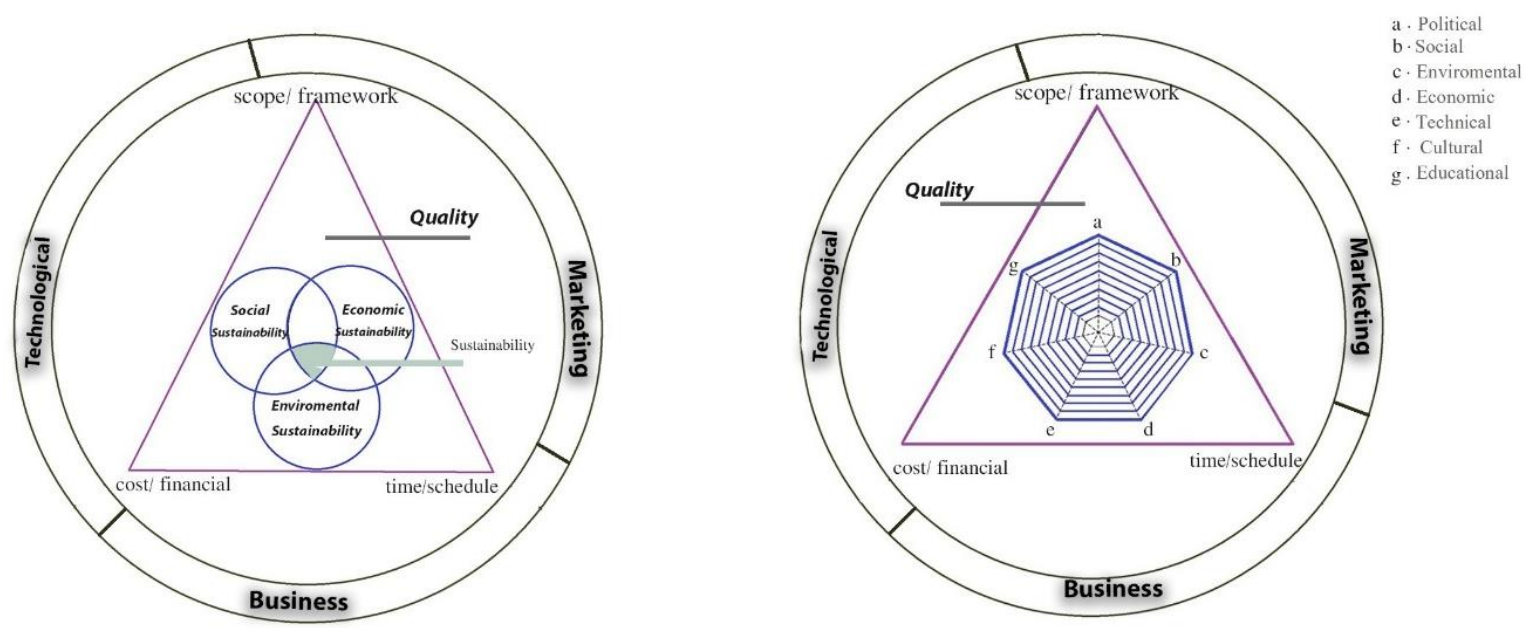

Figure 9. DR-ISPM model.

\subsection{Towards Sustainable Livable Urban Settings}

Sustainable livable urban setting is the best solution to improve quality of citizens' life through reducing the impacts of urbanization challenges. Alongside sustainability, other tools and techniques are required to achieve sustainable development and design such modern areas.

The other tool needed for creating such areas is a comprehensive strategic urban plan including project management, infrastructure, and value engineering.

Based on these two indicators (sustainability and comprehensive strategic urban plan), the DSR (Doost Mohammadian, Sustainability, Rezaie), model as an innovative solution to create sustainable 
livable urban areas is presented by authors. This model was introduced by the authors at the sixth International Conference on Civil, Architectural and Environmental Sciences as a new concept for urban living. Generally, it presents that sustainability and a comprehensive strategic plan (project management is an element of it) could create new urban settings with a high quality of life, livability, and sustainability. According to this theory, besides sustainability, project management and innovation, other tools such as infrastructure including technology, digitalization, mobility, social and cultural capital and value engineering are required to achieve sustainability and high quality of life in an urban setting.

Fundamentally, this model is concerned with utopia cities needed for a high quality of human life. Such cities are not only aligned with sustainable development, but also are creating areas with a high livability through supplying human demands. Utopia cities are based on sustainability, wealth and ubiquitous life that are able to struggle with urbanization challenges, supply human demands, and improve the livability of citizens.

The DSR model is an innovative strategy to create a modern urban area for living through sustainability and a comprehensive urban plan. Sustainable innovative project management is introduced as one of the tools to design a proper strategic plan.

The Figure 10 presents how sustainable livable urban settings could be created:

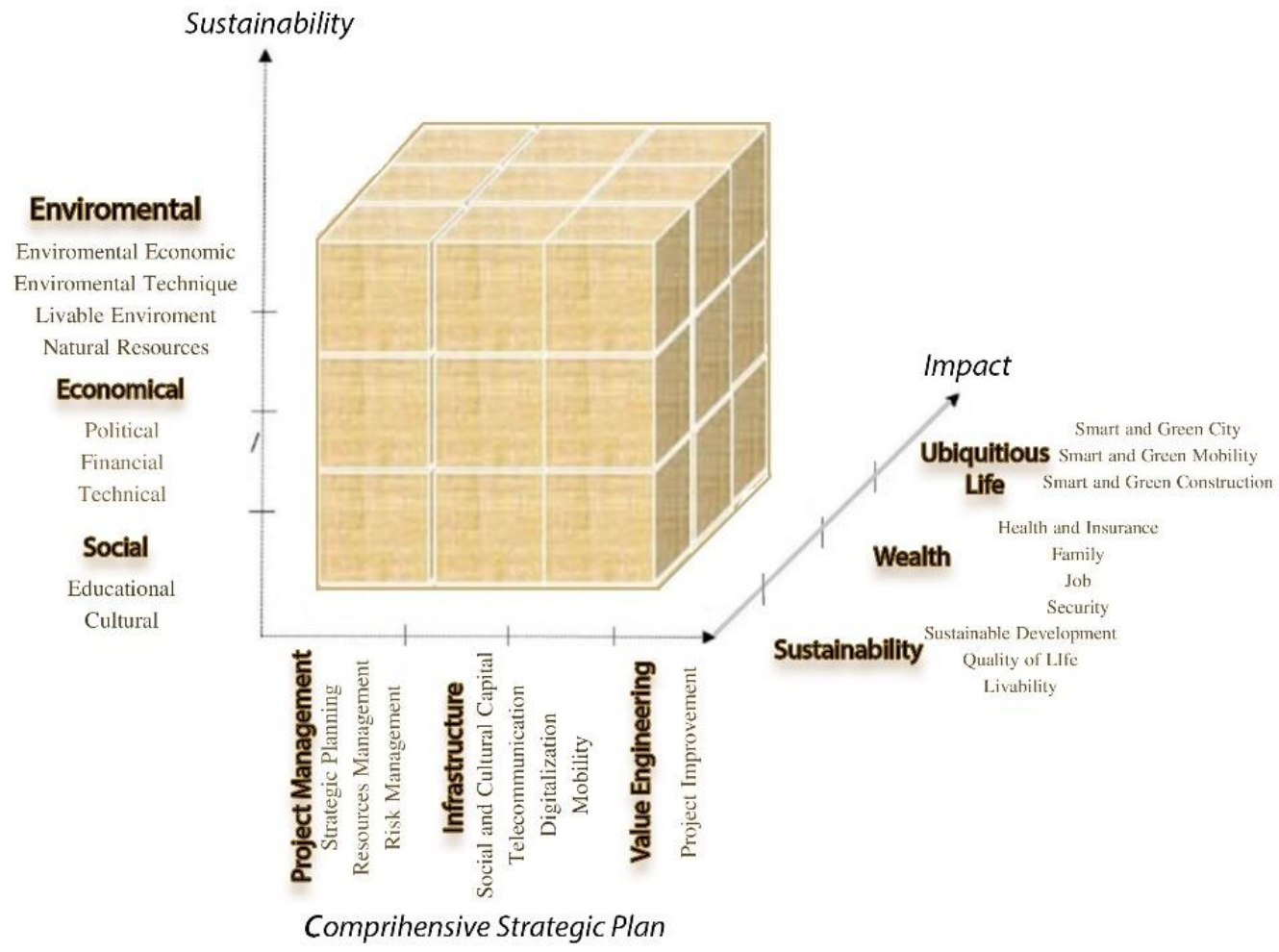

Figure 10. DSR model [16].

Based on this theory, innovative sustainable project management is just one of the tools required to create sustainable livable urban areas. To design such modern areas different tools such as blue-green strategies based on environmental sustainability, successful SMEs to develop economic sustainable, and vocational training towards sustainable education are needed to create sustainable urban areas with high quality of livability and life that could investigated in future studies.

\subsection{Challenges and Solutions}

The most important challenges that the world confronts is risks that threaten quality of life and livability of the world. It is declared that urbanization challenges are the main reasons for these risks. 
These challenges make it difficult to supply human needs, deplete resources, create health challenges, instability, insecurity, environmental challenges, etc., which lessen the quality of livability and life. So, it is vital to find out solutions to tackle these risks.

Creating a sustainable and livable urban area and sustainable development are realized as the main solutions. Paths to design such areas should be investigated. In this research, innovative sustainable project management is introduced as a tool to design such modern cities.

\section{Conclusions and Future Studies}

Nowadays, quality of life and livability are endangered in urban settings through urbanization. A rapid and unplanned urbanization creates severe problems, especially if planning efforts cannot cope with the influx of new inhabitants. The spread of disease, potential water crises, and risks to critical infrastructure, climate change, economic difficulties and social instability are the most important problems which could threat people's lives. These problems have impacts on quality of life and livability and make them worse by disrupting human needs based on Maslow's pyramid. So, it is vital to struggle with urbanization challenges in order to improve quality of life and livability. Sustainable development is the best solution to improve livability in urban settings. Based on the authors' researches, creating a modern, sustainable, and livable setting is the path to achieve sustainable development. Such areas are able not only to achieve sustainable development to improve quality of life, but also to make the world a better place for living.

Suggested urban areas are based on sustainable infrastructure that is related to sustainable designing, building, and operating in ways to develop sustainable social, economic and ecological processes that are required to maintain human equity, diversity, and the functionality of natural systems. In particular, sustainable and livable urban areas provide opportunities to improve quality of life and livability. To design such areas, different parameters like sustainability, comprehensive strategic urban plans, and high technologies are required. It is considered that sustainability, urban planning and good governance with effective regulatory frameworks could deal with urbanization challenges, improve the supply of human needs, and generally enhance quality of life.

In this research, innovative sustainable project management is introduced as a tool to design modern sustainable and livable cities.

In this research, models concerned on innovative sustainable project management are proposed as keys to struggle with these problems. Good governance and management provide appropriate infrastructure and public services, which range from the capacity to contain infectious disease to the challenges of building climate-resilient cities. Therefore, sustainable project management is a proper solution to deal with urbanization problems. In addition, innovation could help project management to improve its goals by creating new ideas or improving old processes. Fundamentally, innovation creates the best and fastest ways to improve quality of life. The DR-ISPM model as a theory to gain innovative sustainable project management is introduced in this theory. In addition, the DSR model as a strategy to create modern sustainable and livable urban areas with a high quality of life is presented. It is realized that such areas are the best solution to struggle with urbanization challenges in order to develop sustainability and improve livability and quality of life towards a better setting for living.

There are several limitations and shortcomings of this paper. The setting and managing of interview appointments was a problem which leads to a delay in the schedule of the research. In addition, due to the short timescale of the research in regard with the research area, the authors might not be able to study enough in the field, which might bring a broader view to the issue. Based on broader research, there are more issues and indicators related to quality of life and livability that are not be mentioned in this study. Furthermore, exploring more case studies could provide more strategies about how to improve quality of life and livability in urban settings.

There are more innovative models like the TRIZ algorithm and IMP3rove as innovation management that are not explored in this research. In future studies these models could be probed, and innovative models based on them could be designed as a new solution to improve quality of 
life and livability. Interviews and questionnaires will be added to future researches as a tool to gain more reliable data about this phenomenon. In addition, other tools named in this research such as a comprehensive strategic urban plan could be explored in future studies.

Author Contributions: Investigation, F.R.; supervision, H.D.M.; visualization, H.D.M. and F.R.; writing一original draft, F.R.

Funding: This research received no external funding.

Conflicts of Interest: The authors declare no conflict of interest.

\section{References}

1. Hernandez, M. Basic concept of innovation and innovation management. In Head of Technology and Innovation; Ericson Espana: Barcelona, Spain, 2010.

2. Tohidi, H.; Jabbari, M. Different Stages of Innovation Processes. Procedia Technology, 2011; Volume 1. Available online: https://www.sciencedirect.com (accessed on 20 December 2012).

3. Sengupta, J. Theory of Innovation: A New Paradigm of Growth; Springer: Berlin/Heidelberg, Germany, 2014.

4. Kylliäinen, J. Key Innovation Management Models and Theories. 2018. Available online: https://www.viima. com (accessed on 6 September 2018).

5. Clayton, C. The Innovators Dilemma: When New Technologies Cause Great Firms to Fail; Harvard Business School: Boston, MA, USA, 1997.

6. Paradis, Z.; Mc Gaw, D. Naked Innovation-Uncovering a Shared Approach for Creating. Master's Thesis, IIT Institute of Design, Chicago, IL, USA, 2007.

7. Kotsemir, M.; Meissner, D. Conceptualizing the Innovation Processes-Trends and Outlooks; National Research University Higher Schools of Economics (HSE): Moscow, Russia, 2013.

8. Zartha1, J.; Montes, J.; Vargas, E.; Palacio, J.; Hoyos, J. Innovation Management Models Prioritization of Variables for the Assessment of the Innovation Management Model in Organizations from the Productive Sector. Indian J. Sci. Technol. 2018, 11, 10. [CrossRef]

9. Khaledabadi, H. Innovation Management: Technologies strategies for Sustainable Vehicle Development. Master's Thesis, KTH Industrial Engineering and Management, Stockholm, Sweden, 2008.

10. Eversheim, W.; Baessler, E.; Breuer, T. Integrated Innovation Management. In Innovation Management for Technical Products Systematic and Integrated Product Development and Production Planning; Eversheim, W., Ed.; Springer: Berlin/Heidelberg, Germany, 2008.

11. Likar, B.; Fatur, P. Innovation Management, 1st ed.; Korona plus d.o.o.-Institute for Innovation and Technology: Ljubljana, Slovenia, 2013.

12. Martens, M.; Carvalho, M. Key factors of sustainability in project management context: A survey exploring the project managers' perspective. Int. J. Proj. Manag. 2017, 35, 1084-1102. [CrossRef]

13. Feil, A.; Schreiber, D. Sustainability and sustainable development: Unraveling overlays and scope of their meanings. Cad. EBAPE. BR 2017, 15, 667-681. [CrossRef]

14. Chapter 2: Towards sustainable development. In Our Common Future, Brundtland Report; United Nation World Commission on Environment and Development: Oslo, Norway, 1987.

15. Basiago, A.D. Economic, social, and environmental sustainability in development theory and urban planning practice. Environmentalist 1998, 19, 145-161. [CrossRef]

16. Doost Mohammadian, H.; Rezaie, F. An applied comparative study about the countries with low sustainability and high $\mathrm{CO}_{2}$-emission and advanced sustainability knowledge in Europe and giving practical models to improve and implement sustainability solutions (case study: Germany and Iran). In Proceedings of the 6th International Conference on Civil, Architectural and Environmental Sciences, Stockholm, Sweden, 19 June 2019.

17. Downey, J. Innovation Management; CIMA: London, UK, 2007.

18. Tamak, R. Use of Critical Success Factors in an Integrated Project Management Model to Improve the Chances of Project Success of a Sustainability Oriented Highway Project during the Exploration and Planning Phase. Master's Thesis, Delft University of Technology, Delft, The Netherlands, 2017.

19. Riemer, S.; Meyer, S. Integrating sustainability in project management-A practical approach. In Strategies to Sustainability; Harvard Business Press: Cambridge, MA, USA, 2009. 
20. Tiron, A.; Dragu, M. Chapter 7: Project Success by Integrating Sustainability in Project Management. In Sustainability Integration for Effective Project Management; Silvius, G., Tharp, J., Eds.; IGI Global: Hershey, PA, USA, 2013.

21. Ruen, K. The Quality of Life and the Environment. In Proceedings of the Asia Pacific International Conference on Environment-Behavior Studies, Famagusta, North Cyprus, 7-9 December 2011.

22. Van Poll, R. The Perceived Quality of the Urban Residential Environment. A Multi-Attribute Evaluation; Rijksuniversiteit Groningen: Groningen, The Netherlands, 1997.

23. Bullock, C.; Brereton, F.; O'Neill, J.; Clinch, P.; Russell, P. Quality of Life and the Environment; Environmental Protection Agency: Wexford, Ireland, 2008.

24. Heylen, K. Livability in Social Housing: Three case studies in Flanders. In Proceedings of the Conference of ENHR for Workshop Residential Environments and People, Ljubljana, Slovenia, 2-5 July 2006.

25. Shamsuddin, S.; Abu Hassanb, N.; Bilyaminb, S. Walkable Environment in Increasing the Livability of a City. In Proceedings of the ASEAN Conference on Environment-Behavior Studies, Bangkok, Thailand, 16-18 July 2012.

26. HerRman, T.; Lewis, R. What is Livability? SCI Research Director; University of Oregon: Eugene, OR, USA, 2017.

27. Momtaz, R.; Elsemary, Y. Qualitative Conceptions of Livability between Theory and Applications in Egypt. In Proceedings of the International Conference on IT, Architecture and Mechanical Engineering, Dubai, UAE, 22-23 May 2015.

28. Giap, T.; Thye, W.; Grace, A. A new approach to measuring the livability of cities: The Global Livable Cities Index. World Rev. Sci. Technol. Sustain. Dev. 2014, 11, 176-196. [CrossRef]

29. Berryman, M.; Wickramasuriya, R.; Lam, V.; Cao, V.; Perez, P. Modeling and Data Frameworks for understanding Infrastructure Systems through Systems-Of-Systems Lens. In Proceedings of the Conference of International Symposium for Next Generation Infrastructure, Wollongong, Australia, 1-4 October 2013.

30. Cho, M. Clinical approach to quality of life in children with end-stage renal disease. Korean J. Pediatr. 2013, 56, 323. [CrossRef] [PubMed]

31. Doost Mohammadian, H. Improvement of Kiwi and Kampenhood Methodology; Technical Report, (used in many Master thesis For example "A Study of Consumer Behavior and Market Intelligence Strategy of Nestle in China" by Ji fang in 2016); FHM University: Bielefeld, Germany, 2010.

32. Maslow, A.H. A Theory of Human Motivation. Psychol. Rev. 1943, 50, 370-396.

33. Horisch, J.; Freeman, E.; Schaltger, S. Applying Stakeholder Theory in Sustainability Management: Links, Similarities, Dissimilarities, and a Conceptual Framework. Org. Environ. 2014, 27, 328-346. [CrossRef]

34. Figgie, F.; Hahn, T.; Schaltegger, S.; Wagner, M. The Sustainability Balanced Scorecard—Linking sustainability management to business strategy. Bus. Strateg. Environ. 2002, 11, 269-284. [CrossRef]

35. Doost Mohammadian, H.; Rezaie, F. An Applied Study of Sustainability plus, Digitalization, Urban Planning and Environmental challenges-Key to Green Ubiquitous Cities \& Mobility as a new concept of Urban Living (case study: Songdo and Seoul). In Proceedings of the 6th International Conference on Civil, Architectural and Environmental Sciences, Stockholm, Sweden, 19 June 2019.

36. Al-Thani, S.; Amato, A.; Koc, M.; Al-Ghamadi, S. Urban Sustainability and Livability: An Analysis of Doha's Urban form and Possible Mitigation Strategies. Sustainability 2019, 11, 786. [CrossRef]

37. Mederly, P.; Novacek, P.; Topercer, J. Sustainable Development Assessment Quality and Sustainability of Life Indicators at Global, National and Regional Level. 2003. Available online: https://www.researchgate.net (accessed on 19 October 2003).

38. Chivot, E. Livability and Sustainability in Large Urban Regions; Hague Centre for Strategic Studies and TNO: The Hague, The Netherlands, 2011.

39. Gazzola, P.; Querci, E. The Connection between the Quality of Life and Sustainable Ecological Development. Eur. Sci. J. 2017, 13, 361-375.

40. Turkoglu, H. Sustainable Development and Quality of Urban Life. Soc. Behav. Sci. 2015, 202, 10-14. [CrossRef]

(C) 2019 by the authors. Licensee MDPI, Basel, Switzerland. This article is an open access article distributed under the terms and conditions of the Creative Commons Attribution (CC BY) license (http://creativecommons.org/licenses/by/4.0/). 